\title{
Association between screen time and body mass index among university students
}

\author{
Associação entre tempo de tela e índice de massa corporal entre \\ estudantes universitários \\ Deivendran Kalirathinam (D)1 $₫$, Tan Xin Hui ${ }^{\mathbb{D} 1}$, Swapneela Jacob ${ }^{(\mathbb{D} 1,}$, Sathish Kumar Sadagobane (D)1, \\ Martin Ebenezer Chellappan (D) 1 \\ 1 University Tunku Abdul Rahman, Jalan Sungai Long, Faculty of Medicine and Health Sciences, Department of Physiotherapy. Selangor, Malaysia.
}

How to cite this article:

Kalirathinam D, Hui TX, Jacob S, Sadagobane SK, Chellappan ME. Association between screen time and body mass index among university students. Sci Med. 2019;29(3):e33149. https://doi.org/10.15448/1980-6108.2019.3.33149

\section{ABSTRACT}

AIMS: Screen time has been proven to be associated with overweight and obesity among pediatric. However, the relationship between these two variables has not been confirmed among university students in Malaysia who are having increasing screen time. Hence, this study is conducted to examine the association between screen time and body mass index (BMI) among university students.

METHODS: A total of 390 university students (female=236, male=154) with a mean age of 20.17 years old were involved in this study. They completed the Screen Time Based Sedentary Behaviour Questionnaire for total screen time assessment. Body height and weight were measured to calculate body mass index (BMI).

RESULTS: Prevalence of overweight and obesity were not high among university students (12.3\% and 4.4\%). Male subjects have generally higher BMI compared to female subjects. The smartphone was the most common device owned by subjects (33\%). The screen time of subjects was high as there were $97.4 \%$ of subjects fell under the category of high screen time ( $>2$ hours). However, screen time was not significantly associated with BMI $(\mathrm{p}=0.36)$. The only variable which associated with screen time was the devices owned by subjects $(\mathrm{p}=0.001)$.

CONCLUSIONS: Screen time was not significantly associated with BMI among university students. Future study should include the relationship of other factors on BMI among university students.

KEYWORDS: Screen time; body mass index.

\section{RESUMO}

OBJETIVOS: Foi demonstrado que o tempo de tela está associado ao sobrepeso e à obesidade nos pacientes pediátricos. No entanto, a relação entre essas duas variáveis não foi confirmada entre estudantes universitários na Malásia, que estão tendo um aumento no tempo de tela. Desse modo, o objetivo desses estudo é avaliar a associação entre tempo de tela e o indice de maasa corporal (IMC) entre estudantes universitários. MÉTODOS: Um total de 390 estudantes universitários (sexo feminino=236, masculino=154) com idade média de 20,17 anos foram envolvidos neste estudo. Eles completaram o Questionário de Comportamento Sedentário Baseado no Tempo de Tela para avaliação total do tempo de tela. A altura corporal e o peso foram medidos para calcular o índice de massa corporal (IMC).

RESULTADOS: A prevalência de sobrepeso e obesidade não foi alta entre os universitários (12,3\% e 4,4\%). Indivíduos do sexo masculino têm geralmente um IMC mais alto em comparação com indivíduos do sexo feminino. O smartphone foi o dispositivo mais comum de propriedade dos sujeitos (33\%). O tempo de tela dos participantes foi alto, pois $97,4 \%$ dos sujeitos caíram na categoria de tempo de tela alta ( $>2$ horas). No entanto, o tempo de tela não foi significativamente associado ao IMC $(\mathrm{p}=0,36)$. A única variável associada ao tempo de tela foram os dispositivos pertencentes aos sujeitos $(\mathrm{p}=0,001)$.

CONCLUSÕES: O tempo de tela não foi significativamente associado com o IMC entre os estudantes universitários. Estudos futuros devem incluir a relação de outros fatores sobre o IMC entre estudantes universitários.

DESCRITORES: Tempo de tela; índice de massa corporal. 
Abbreviations: BMI, body mass index; TV, television; UTAR, Universiti Tunku Abdul Rahman.

\section{INTRODUCTION}

Screen time refers to the duration of time spent in front of the screen of an electronic device, such as television (TV), laptop, desktop, electronic games, hand-held devices such as smartphone and tablet and other visual devices [1]. In this modern world, surviving without electronic devices especially smartphone has become almost impossible for a human being. Smartphone appears as the most chosen device among all electronic devices as it is mobile and multifunctioned. According to the Hand Phone Users Survey 2017, the percentage of smartphone users in Malaysia continues to grow from $68.7 \%$ to $75.9 \%$ during the year of 2016 to 2017 [2]. This is mostly due to the increasing use of and dependence on the applications available on their smartphones. They spend about 3 hours/day on their devices on average [3]. Among smartphone users, communication remains as the topone activity. The majority (98.5\%) of them are using their device for text messaging and voice over-the-top services, such as WeChat, WhatsApp and Facebook Messenger [2].

New Straits Times reported in 2016 that Malaysian digital consumers are spending an average of almost 14 hours a day on their electronic devices with $87 \%$ of them are surfing the Internet [4]. Social media use on the internet has become a dominating activity among smartphone users especially university students. Body Mass Index (BMI) is one of the anthropometric measurements which widely performed to evaluate overweight and obesity. BMI is calculated by using the division of body weight in kilograms by body height in meter square [5]. BMI is chosen as a measurement for classification of the study group as it is a measure of the ratio for the body weight with body height and it can be obtained easily from the public. It is an acceptable representation for thinness and fatness of the body, and directly associated with the risk of well-being and rate of death in many populations [6].

Overweight and obesity is seen as a growing health issue in most of the developing countries including Malaysia. According to the World Health Organization, overweight and obesity are defined as a condition where there is abnormal or excessive fat accumulation which produced by inequality of energy between calories uptake and expenditure [7]. Results showed that there were more than 1.9 billion (39\%) adults who are equal to or more than 18 years old were overweight in the year 2016. Of these, over 650 million $(13 \%)$ adults were obese. The international prevalence of obesity has almost tripled within 40 years which is from 1975 to 2016 [7]. Meanwhile, the prevalence of overweight and obesity were found to be $33.6 \%$ and $19.5 \%$ respectively in Malaysia [8] the prevalence of overweight and obesity were found to be $33.6 \%$ (95\% CI $=32.2,35.0$. Overweight and obesity appear as the major cause of non-communicable diseases, including cardiovascular disease, hypertension, type 2 diabetes mellitus, dyslipidemia, gallbladder disease, musculoskeletal disorders such as osteoarthritis and also some cancers [9]. Thus, the growing problem of overweight and obesity in Malaysians should be taken earnestly as it can burden the health care systems and lower the quality of life. Watching TV, using a smartphone and playing computer games are mainly low-energy activities. This leads to an increased risk of weight gain and changes in BMI among them. Hence, the present study aimed to investigate the relationship between screen time and BMI among undergraduate students.

\section{METHODS}

This study was a cross-sectional which conducted at Universiti Tunku Abdul Rahman (UTAR) Sungai Long Campus. Subjects were recruited from all faculties in UTAR Sungai Long Campus. Informed consent was obtained and verified before each participant's enrolment. A detailed explanation about the research objective and procedure was clarified by before their participation. Subjects were asked to sign the consent form and fill up the demographic data before they fill in the questionnaire. Then, they were required to answer the Screen Time Based Sedentary Behaviour Questionnaire. Body height and weight of the subject were measured by the Marsden HM-201M Manual Height Measure (Rotherhan, United Kingdon) in the Physiotherapy Centre. Recruited subjects were those who able to meet the inclusion criteria which includes both male and female students in UTAR Sungai Long Campus who willing to participate, while those who were taking medicine which may trigger weight gain and unwilling to sign the consent form were excluded. Screen Time Based Sedentary Behaviour Questionnaire was used to measure the total screen time. It was given to the participants through a face-to-face paper-based survey. Subjects were categorized into low screen time $(<2$ hours per day) and high screen time ( $>2$ hours 
per day). BMI was calculated from the body weight and height measured. Participants were categorized into 3 groups, which are normal, overweight, and obesity according to their BMI. The Research Ethics Committee of the UTAR U/SERC/135/2018 approved this study.

Data analysis was performed with IBM SPSS 24.0 Statistics. The result is statistically significant when $\mathrm{p}<0.05$. Descriptive statistics were used to analyse the demographic data of the subjects, height, weight and BMI of subjects, devices owned by subjects, total screen time, screen time on different activities of subjects during weekday and weekend. Moreover, inferential statistics was applied by using the Chisquare test in order to find out the association between the two variables which are BMI and screen time. Spearman correlation analysis was done to determine the association between devices owned by the subjects and screen time.

\section{RESULTS}

A total of 390 subjects, 154 (39.5\%) males and 236 (60.5\%) female, completely filled the questionnaire. The age range of respondents was from 17 to 25 years old. The mean age of the respondents was $20.2 \pm 1.6$ years old. The mean height of subjects was $165 \pm 8 \mathrm{~cm}$, mean weight was $59.0 \pm 13.3 \mathrm{~kg}$ and mean BMI was $21.7 \pm 4.1 \mathrm{~kg} / \mathrm{m}^{2}$. Most of the subjects fall under the category of normal BMI ( $\mathrm{n}=325 ; 83.3 \%$ ), followed by overweight $(n=48 ; 12.3 \%)$, and obesity $(n=17 ; 4.4 \%)$.

The device that mostly owned by subjects was smartphone $(\mathrm{n}=424,33 \%)$, followed by laptop / netbook / notebook $(n=394 ; 30.7 \%)$, television $(n=196,15.3 \%)$, then PC / desktop ( $n=119,9.3 \%)$, tablet $(n=96,7.5 \%)$ and video game console $(\mathrm{n}=55,4.3 \%)$. On average, each subject owned at least 3 devices.

There were 380 (97.4\%) subjects fell under the category of high screen time ( $>2$ hours) while there were only $10(2.6 \%)$ of subjects fell under the category of low screen time $(<2$ hours). During a typical weekday, subject spent the longest time surfing Internet for non-study reasons (hobbies) which has a mean of $153 \mathrm{~m} 36 \mathrm{~s} \pm 75 \mathrm{~m} 27 \mathrm{~s}$ in average, followed by surfing on Internet for study reasons, studying, playing computer games, watching TV and playing video games which having mean of $91 \mathrm{~m} 37 \mathrm{~s} \pm 70 \mathrm{~m} 31 \mathrm{~s}$, $86 \mathrm{~m} 43 \mathrm{~s} \pm 72 \mathrm{~m} 20 \mathrm{~s}, 49 \mathrm{~m} 48 \mathrm{~s} \pm 73 \mathrm{~m} 34 \mathrm{~s}, 33 \mathrm{~m} 36 \mathrm{~s} \pm 55 \mathrm{~m} 39 \mathrm{~s}$ and $9 \mathrm{~m} 35 \mathrm{~s} \pm 38 \mathrm{~m} 37 \mathrm{~s}$ respectively.

The highest screen time activity during a typical weekend was surfing the Internet for non-study reasons (hobbies) which had a mean of $172.33 \pm 72.87$ minutes.
It was followed by surfing on the Internet for study reasons, studying, playing computer games, watching $\mathrm{TV}$ and playing video games which had a mean of $80.86 \pm 70.50,73.65 \pm 69.37,59.14 \pm 82.80,57.72 \pm 79.10$ and $11.33 \pm 43.08$ minutes respectively.

The prevalence of normal weight was higher among subjects who are had low screen time 10 (100.0\%) compared to subjects who had high screen time 315 $(82.9 \%)$. Moreover, the prevalence of overweight and obesity were also higher in subjects who had high screen time which is $48(12.6 \%)$ and $17(4.5 \%)$ subject respectively as no subject having low screen time falls under these two categories. The difference in the prevalence of normal weight, overweight and obesity between total screen time category was not significant $(\mathrm{p}=0.36)$. Thus, there was no association between total screen time and BMI of subjects.

Spearman correlation analysis was done to determine the association between devices owned by the subjects and screen time. Based on the mean number of devices owned by the subjects was $3.3 \pm 1.5$ and the mean screen time was $433 \mathrm{~m} 29 \mathrm{~s} \pm 181 \mathrm{~m} 39 \mathrm{~s}$. There was a correlation between devices owned by the subjects and their screen time as $r_{s}$ value was 0.170 . There was a positive linear relationship between the number of devices owned by the subjects and screen time as the line was going up. The positive linear relationship was considered a weak relationship. The correlation was statistically significant at $\mathrm{p}=0.001$. Therefore, an association was found between devices owned by the subjects and their screen time.

\section{DISCUSSION}

The main finding was that the two main variables which were screen time and BMI were not associated. This was in contrast with several studies which concluded that there was a positive association between screen time and BMI. The difference in the results obtained might be due to several reasons which influence the data collection phase. First, the methodology is the key factor which will affect the results obtained. The approach which the previous researchers chose to distribute their questionnaire was different from the current study. There were two studies which use online survey form through mailing $[10,11]$. Instead, Duncan et al. conducted their survey by using phone calls [12]. However, the current study used face-to-face paper-based survey method to distribute the questionnaire. This will be a better method compared to others [13]. By using this method, the researcher can face the subjects directly 
and explain the research title and objective clearly. This will be a more convincing method for participants to involve in the study instead of emailing as emails might be overlooked. Subjects also will be more focus on the words which spoken by the researchers and their enthusiasm during the interview [14]. Therefore, the face-to-face method of survey is more reliable than other methods of distributing the questionnaire. Furthermore, the instrumentation for outcome measure also plays an important role in affecting the results. The study done by Bickham et al. used Seca stadiometer to measure body height and Detecto scale to measure body weight [15]. The instruments which used by Laurson et al. were portable stadiometer and strain gauge scale [16]. Whereas for the current study, the instrument used was Marsden HM-201M Manual Height Measure which combined measurement of body weight and height. The difference in the instrument to measure subjects' body weight and height will greatly influence the results obtained. This is due to the random error which might be happening during measurement. Moreover, the targeted population in the current study was different from previous studies. The age group of the study done by Liao et al. was 30 to 59 years old [11] while Falbe et al. were 9 to 15 years old [10]. In the current study, subjects were between 18 to 25 years old. This might be one of the reasons which caused the difference in the results obtained. Besides, the study done by Laurson et al. had achieved a balance between male and female. They found an association between screen time and BMI [16]. As the proportion of male and female subjects was not balanced in the current study, the sex difference when comparing between variables cannot be distinguished.

Nevertheless, there were also a few studies recently which supported the result of this study. The study done by de Lucena et al. concluded that no significant association was found between excess screen time and increase in body weight [17]. There were two studies in 2014 which did not found a significant association between screen time and BMI $[18,19]$. The reason behind this is because the determinants which influence changes in BMI are multifactorial [20]. The possible factors which might cause changes in BMI are dietary intake, involvement in physical activity and genetic factor. There is no research which found a definite factor in causing weight gain and increasing in BMI. Therefore, with the results obtained in this study, we can only conclude that screen time was not the factor which contributes to weight gain and changes in BMI as there are other factors which have a stronger association with the changes in BMI.
Based on the result analysed, the device owned by the subjects was strongly correlated with screen time ( $\mathrm{p}=0.001)$. This means that the increase in devices owned will leads to an increase in screen time. The relationship between the two findings, which are smartphone appeared as the most device owned, and subject spent the longest time on surfing the Internet can be explained by the finding of Internet Users Survey 2017 that smartphone was the most chosen device used to connect Internet. A student will normally use their smartphone to surf the Internet as it is lightest among all devices, mobile and contains a different type of applications. They can easily access the Internet whenever they are and whenever they want. In their age, social media use is the dominating activity with the use of a smartphone. They also spent a long-time watching videos on YouTube. As the videos on YouTube will be played automatically, they will end up with few hours of watching videos unconsciously. Increased number of devices owned will certainly increase the duration of time spent in front of the screen. Based on the finding in this study, each subject owned at least 3 devices on average. This can explain the increasing screen time among university students nowadays as they can own more than one device compared to university students in the older generation. Thus, the probability of facing the screen will be increased when the device owned increased. More time will be spent by students on their electronic devices for study purpose and entertainment.

As this is a cross-sectional study design, the causal relationship between the two main variables which are screen time and BMI cannot be investigated. Moreover, as the questionnaire is based on self-reporting data, there could be bias and error in recalling the exact time spent on each screen activity. This cannot be avoided as objective monitoring of screen time was not practical and not feasible. The number of subjects in each gender should be more balance so that the sex differences between the variables can be distinguished.

The main strength in this study is that the screen time was assessed separately by weekday and weekend so that an average time can be calculated by using formula. This is important as the time spent on screen activity is different during weekend and weekday. Furthermore, the objective measure of body weight and height is the main key to this study. This is because of the inaccuracy of self-reported data where subjects might over or underreport their body weight and height. Objective measurement with the same machine can maintain the consistency and reliability of data obtained. 
This study has concluded that the screen time was not associated with BMI of the subjects. The only variable which associated with screen time was the devices owned by subjects. This is due to the other possible factors which might influence the weight gain and changes in BMI including dietary habit and physical activity. Thus, future study should investigate the relationship between those variables in order to find out the variable which is most strongly associated with BMI.

\section{NOTES}

This study is results of Undergraduate project Carried in University Tunku Abdul Rahman.
Funding

This study did not receive financial support from external sources.

Conflicts of interest disclosure

The authors declare no competing interests relevant to the content of this study.

\section{Authors' contributions}

All the authors declare to have made substantial contributions to the conception, or design, or acquisition, or analysis, or interpretation of data; and drafting the work or revising it critically for important intellectual content; and to approve the version to be published.

Availability of data and responsibility for the results

All the authors declare to have had full access to the available data and they assume full responsibility for the integrity of these results.

\section{REFERENCES}

1. Olson J, Aldrich H, Callahan TJ, Matthews EE, Gance-Cleveland B. Characterization of childhood obesity and behavioral factors. J Pediatr Health Care. 2016;30(5):444-52. https://doi.org/10.1016/J.PEDHC.2015.10.009

2. Malaysian Communications and Multimedia Commission. Hand phone users survey 2017: statistical brief number twenty-two [Internet]. Cyberjaya: MCMC; 2017 [capturado em 29 ago. 2019]. Disponível em: https:/www.mcmc. gov.my/skmmgovmy/files/7a/7a76ae49-265b-44d4-a7cc-16a22afa784d/files/assets/basic-html/page-2.html

3. Malaysians glued to smartphones for three hours a day, study shows [Internet]. Malay Mail. 20 Jan. 2016 [capturado em 29 ago. 2019]. Disponível em: https://www.malaymail.com/s/1044649/malaysians-glued-to-smartphones-forthree-hours-a-day-study-shows

4. Bernama. Malaysians spend 14 hours daily on digital devices: survey [Internet]. New Straits Times. 16 Nov. 2016 [capturado em 29 ago. 2019]. Disponível em: https://www.nst.com.my/news/2016/11/189176/malaysians-spend-14hours-daily-digital-devices-survey

5. World Health Organization. Body mass index - BMI [Internet]. Geneva: WHO; 2018 [capturado em 29 ago. 2019 ]. Disponível em: http://www.euro.who.int/en/health-topics/disease-prevention/nutrition/a-healthy-lifestyle/body-massindex-bmi

6. Abdelaal M, le Roux CW, Docherty NG. Morbidity and mortality associated with obesity. Ann Transl Med. 2017;5(7):161. https://doi.org/10.21037/atm.2017.03.107

7. World Health Organization. Obesity and overweight [Internet]. Geneva: WHO; 2018 [capturado em 29 ago. 2019 ]. Disponível em: http://www.who.int/en/news-room/fact-sheets/detail/obesity-and-overweight

8. Mohamud WN, Musa KI, Khir AS, Ismail AA, Ismail IS, Kadir KA, Kamaruddin NA, Yaacob NA, Mustafa N, Ali O, Isa SH, Bebakar WM. Prevalence of overweight and obesity among adult Malaysians: an update. Asia Pac J Clin Nutr. 2011;20(1):35-41. https://doi.org/10.6133/APJCN.2011.20.1.06

9. Lim KG. A review of adult obesity research in Malaysia. Med J Malaysia. 2016;71(Suppl 1):1-19.

10. Falbe J, Rosner B, Willett WC, Sonneville KR, Hu FB, Field AE. Adiposity and different types of screen time. Pediatrics. 2013;132(6):e1497-505. https://doi.org/10.1542/peds.2013-0887

11. Liao Y, Harada K, Shibata A, Ishii K, Oka K, Nakamura Y, Sugiyama T, Inoue S, Shimomitsu T. Joint associations of physical activity and screen time with overweight among japanese adults. Int J Behav Nutr Phys Act. $2011 ; 8: 131$. https://doi.org/10.1186/1479-5868-8-131

12. Duncan MJ, Vandelanotte C, Caperchione C, Hanley C, Mummery WK. Temporal trends in and relationships between screen time, physical activity, overweight and obesity. BMC Public Health. 2012;12:1060. https://doi. org/10.1186/1471-2458-12-1060

13. Christensen AI, Ekholm O, Glümer C, Juel K. Effect of survey mode on response patterns: comparison of face-toface and self-administered modes in health surveys. Eur J Public Health. 2014;24(2):327-32. https://doi.org/10.1093/ eurpub/ckt067 
14. Holbrook AL, Green MC, Krosnick JA. Telephone versus face-to-face interviewing of national probability samples with long questionnaires: comparisons of respndent satisficing and social desirability responses bias. Public Opin Q. 2003;67(1):79-125. http://dx.doi.org/10.1086/346010

15. Bickham DS, Blood EA, Walls CE, Shrier LA, Rich M. Characteristics of screen media use associated with higher BMI in young adolescents. Pediatrics. 2013;131(5):935-41. https://doi.org/10.1542/peds.2012-1197

16. Laurson KR, Eisenmann JC, Welk GJ, Wickel EE, Gentile DA, Walsh DA. Combined influence of physical activity and screen time recommendations on childhood overweight. J. Pediatr. 2008;153(2):209-14. https://doi.org/10.1016/ j.jpeds.2008.02.042

17. Lucena JMS, Cheng LA, Cavalcante TLM, Silva VA, Farias Júnior JC. Prevalence of excessive screen time and associated factors in adolescents. Rev Paul Pediatr. 2015;33(4):407-14. https://doi.org/10.1016/J. RPPEDE.2015.08.014

18. Laurson KR, Lee JA, Gentile DA, Walsh DA, Eisenmann JC. Concurrent associations between physical activity, screen time, and sleep duration with childhood obesity. ISRN Obes. 2014:204540. https://doi.org/ $10.1155 / 2014 / 204540$

19. Lee ST, Wong JE, Shanita SN, Ismail MN, Deurenberg P, Poh B, Poh BK. Daily physical activity and screen time, but not other sedentary activities, are associated with measures of obesity during childhood. Int J Environ Res Public Health. 2015;12(1):146-61. https://doi.org/10.3390/ijerph120100146

20. Sherwood NE, Jeffery RW, French SA, Hannan PJ, Murray DM. Predictors of weight gain in the pound of prevention study. Int J Obes Relat Metab Disord. 2000;24(4):395-403. https://doi.org/10.1038/sj.ijo.0801169 